\title{
$S n$-wave velocity structure of the uppermost mantle beneath the Australian continent
}

\author{
Zhi Wei, ${ }^{1,2}$ Brian L. N. Kennett ${ }^{3}$ and Weijia Sun ${ }^{1}$ \\ ${ }^{1}$ Key Laboratory of Earth and Planetary Physics, Institute of Geology and Geophysics, Chinese Academy of Sciences, Beijing 100029, China. E-mail: \\ weizhi@mail.iggcas.ac.cn \\ ${ }^{2}$ University of Chinese Academy of Sciences, Beijing 100049, China \\ ${ }^{3}$ Research School of Earth Sciences, Australian National University, Canberra 2601, Australia
}

Accepted 2018 March 16. Received 2017 August 28; in original form 2018 March 13

\begin{abstract}
SUMMAR Y
We have extracted a data set of more than $5000 S n$ traveltimes for source-station pairs within continental Australia, with 3-D source relocation using $P n$ arrivals to improve data consistency. We conduct tomographic inversion for $S$-wave-speed structure down to $100 \mathrm{~km}$ using the Fast Marching Tomography (FMTOMO) method for the whole Australian continent. We obtain a 3D model with potential resolution of $3.0^{\circ} \times 3.0^{\circ}$. The new $S$-wave-speed model provides strong constraints on structure in a zone that was previously poorly characterized. The $S$ velocities in the uppermost mantle are rather fast, with patterns of variation generally corresponding to those for $P n$. We find strong heterogeneities of $S$ wave speed in the uppermost mantle across the entire continent of Australia with a close relation to crustal geological features. For instance, the cratons in the western Australia usually have high $S$ velocities $(>4.70 \mathrm{~km}$ $\mathrm{s}^{-1}$ ), while the volcanic regions on the eastern margin of Australia are characterized by low $S$ velocities $\left(<4.40 \mathrm{~km} \mathrm{~s}^{-1}\right)$. Exploiting an equivalent $P n$ inversion, we also determine the $V_{\mathrm{p}} / V_{\mathrm{s}}$ ratios across the whole continent. We find that most of the uppermost mantle has $V_{\mathrm{p}} / V_{\mathrm{s}}$ between 1.65 and 1.85, but with patches in central Australia and in the east with much higher $V_{\mathrm{p}} / V_{\mathrm{s}}$ ratios. Distinctive local anomalies on the eastern margin may indicate the positions of remnants of mantle plumes.
\end{abstract}

Key words: Structure of the Earth; Australia; Body waves; Seismic tomography.

\section{INTRODUCTION}

Over the last $30 \mathrm{yr}$, there have been extensive deployments of temporary seismic stations across Australia and an expansion of the national seismic network. This has allowed the exploitation of the good distribution of regional earthquakes in the belts around Australia to develop models of mantle structure beneath the continent, whose major features show similar long-wavelength behaviour (e.g. Fishwick et al. 2008; Fichtner et al. 2010; Yoshizawa 2014). This consistency has enabled Kennett et al. (2013) to construct a representative mantle model for the Australian Seismological Reference Model (AuSREM). All of the approaches using surface waves are somewhat sensitive to knowledge of crustal structure, and the mantle component of AuSREM is most reliable from $75 \mathrm{~km}$ downward. Receiver function studies at many seismic stations, coupled with ambient noise tomography and results from earlier refraction experiments have been used to develop the crustal component of AuSREM (Salmon et al. 2013a). The weakest constraints on Australian structure are in the uppermost mantle just beneath the Moho. Sun \& Kennett (2016a) carried out $P n$ tomography exploiting bulletin data to construct a new $P$ wave model for this zone. Here, we use the waveforms of $S n$ phases recorded across the continent to develop a new $S$-wave model down to $100 \mathrm{~km}$ depth with $S n$ tomography, using AuSREM as the initial model. We also build a separate $P$-wave velocity model using a new and enlarged $P n$ traveltime data set. This allows comparison of $P$ and $S$ behaviour in the uppermost mantle.

The $S n$ wave, which is refracted back from the uppermost mantle, usually appears as the first arrival for shear waves in the distance range between $2^{\circ}$ and $15^{\circ}$. We are able to make $S n$ picks for over 5000 source-station pairs within the continent, with a generally good pattern of crossing paths. The range of paths and epicentral distances provides good sampling of the uppermost mantle.

Australia has been an independent island since it broke away from Antarctica around $80 \mathrm{Ma}$. The continent contains some of the oldest formations on Earth in the Archean Yilgarn and Pilbara cratons in Western Australia (Fig. 1). Central Australia is dominated by Proterozoic domains (2500-550 Ma), although there is an Archean core to the South Australian Craton. The Phanerozoic belts in the east (younger than $550 \mathrm{Ma}$ ) represent successive accretions to the continental core. The cratonic regions, which occupy more than two-thirds of Australian continent, typically have lithosphere over 

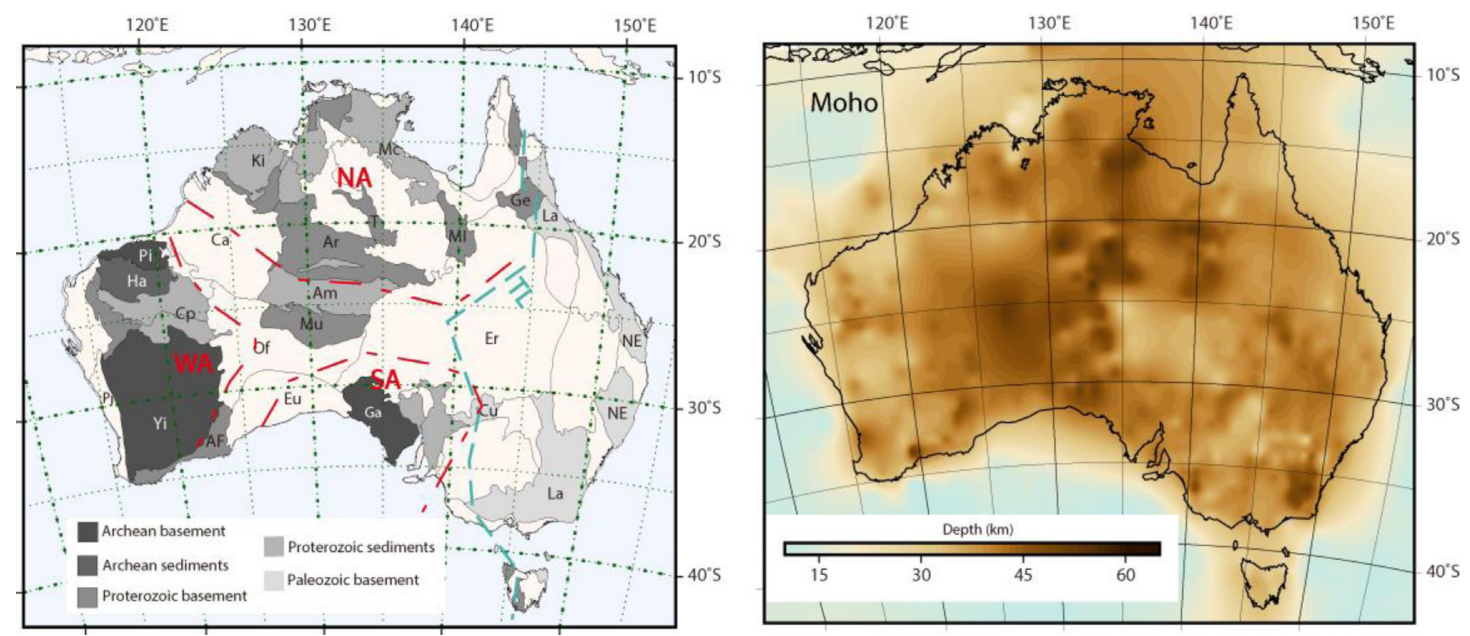

Figure 1. Australian tectonic features and Moho depth. Key to marked features: AF-Albany-Fraser Belt; Ar-Arunta Block; Am—Amadeus Basin; Ca— Canning Basin; $\mathrm{Cp}$ —Capricorn Orogen; $\mathrm{Cu}$-Curnomona Craton; Er-Eromanga Basin; Eu—Eucla Basin; Ga—Gawler Craton; Ge-Georgetown Inlier; Ha—Hamersley Basin; Ki—Kimberley Block; La—Lachlan Orogen; Mc—McArthur Basin; MI—Mt Isa Block; Mu—Musgrave Block; NE—New England Orogen, Of-Officer Basin, Pi—Pilbara Craton, Pj—Pinjarra Orogen; T—Tennant Creek Block; Yi—Yilgarn Craton; NA—North Australian Craton; WAWest Australian Craton; SA—South Australian Craton; TL—Tasman Line.

$200 \mathrm{~km}$ thick. The lithosphere thins under the Phanerozoic zones in the east.

$S n$-wave velocities often tie well to the geological setting. Regions with few recent tectonic activities, such as old basins and cratons, usually have high $S n$ velocities, while low $S n$ velocities are often found in modern orogenic belts or volcanic areas, which are tectonically active (e.g. Nolet et al. 1998; Díaz et al. 2012). For instance, the stable Sichuan Basin in China has high $S n$ velocities (Pei et al. 2007), while Sun \& Kennett (2016b) found that regions around some active volcanoes show rather low $S n$ velocity in eastern China and its surroundings. $S$ wave tomography of the crust and uppermost mantle in eastern China also reveals that there are magma chambers beneath the volcanoes with strong low $S$-wave velocity zones into the upper mantle (Sun et al. 2008). The velocity of shear waves is rather sensitive to temperature (e.g. Goes \& Van der Lee 2002); volatiles or melt may be also be identified by dramatic decrease of the shear velocity (Zielhuis \& Nolet 1994). The velocity ratio between compressional waves and shear waves $\left(V_{\mathrm{p}} / V_{\mathrm{s}}\right)$ is directly related to the Poisson ratio. Comparison of $P$ - and $S$-wave velocity distributions can thus be used to indicate the state of material in the Earth's interior. Low- $V_{\mathrm{s}}$ and high $V_{\mathrm{p}} / V_{\mathrm{s}}$ can be caused by partial melt, while low- $V_{\mathrm{s}}$ and low $V_{\mathrm{p}} / V_{\mathrm{s}}$ may imply the presence of water (e.g. Walck 1988; Nakajima et al. 2001; Conder $\&$ Wiens 2006). High $V_{\mathrm{p}} / V_{\mathrm{s}}$ values can also be related to saturated and highly fractured materials near the surface (Nur \& Simmons 1969). With increase of depth, lower $V_{\mathrm{p}} / V_{\mathrm{s}}$ values can be caused by microcrack closure under increasing pressure (e.g. Nicholson \& Simpson 1985; Walck 1988). The $V_{\mathrm{p}} / V_{\mathrm{s}}$ ratios beneath Australia have been previously been studied using receiver functions, with most values in the upper mantle larger than 1.70 (Shibutani et al. 1996; Clitheroe et al. 2000). In this work, we build a 3-D model of $V_{\mathrm{p}} / V_{\mathrm{s}}$ ratios across the whole continent from the independent inversions for $P$ and $S$ wave speeds in the uppermost mantle.

\section{DATA}

Since 1993 the Australian National University has carried out extensive deployments of temporary seismic stations across Australia, which provide broad-scale coverage of the continent and denser sampling of the southeast. Over the same time period the Australian National seismic network has been augmented, particularly since the great Sumatra-Andaman earthquake of 2004. As a result, we can obtain good coverage of $S n$ propagation across the Australian continent using events within the continent or on its margins.

We have chosen events across Australia with magnitudes larger than 3.5 and whose location is at least $2 \mathrm{~km}$ above the Moho. We used event-station pairs whose separation was between $2^{\circ}$ and $15^{\circ}$. Within this range, we can distinguish $P n$ and $S n$ phases from the crustal $P g$ and $S g$ phases, since $S n$ and $P n$ appear as the first arrivals for their wave types. The seismic waveforms were rotated onto radial, transverse and vertical components relative to the greatcircle path from source to receiver. The radial component mainly contains $P$ and $S V$ wave energy, while $S H$ waves are predominant on the transverse component. We chose the clearest onsets of $S n$ and $P n$ waves on any of the three components as the arrival time for the phase. For $S n$, this means that most readings were taken on the transverse component where there is little influence from the $P$ coda.

In Fig. 2, we illustrate unfiltered three-component seismic waveforms (vertical, transverse and radial) for the $M_{\mathrm{b}} 4.8$ event of 2016 November 6 in Western Australia recorded by six stations. The onsets of these $S n$ and $P n$ phases refracted from the upper mantle carry high frequency energy with group velocities around $4.5 \mathrm{~km} \mathrm{~s}^{-1}$ for $S n$ and $8.0 \mathrm{~km} \mathrm{~s}^{-1}$ for $P n$.

Although, as noted by Huestis et al. (1973), Australia lies among regions with efficient propagation of $S n$, the phase arrival is still not easy to pick. The onset of $S n$ often has relatively small amplitudes and in the high $Q$ cratonic areas there is little difference in frequency between $S n$ and the $P$ coda.

We have experimented with a range of automated picking approaches for picking $S n$ implemented through Obspy, such as ShortTerm to Long-Term Average (STA/LTA) method (e.g. Allen 1978; Trnkoczy 2012), the Z-detector method (e.g. Withers et al. 1998), and method combining an AR-AIC criterion with a STA/LTA algorithm (Akazawa 2004). We have also tried to compute the derivatives of such functions to pick up gradients indicating the arrivals of the phase. Unfortunately, in each case, there are only a limited number 

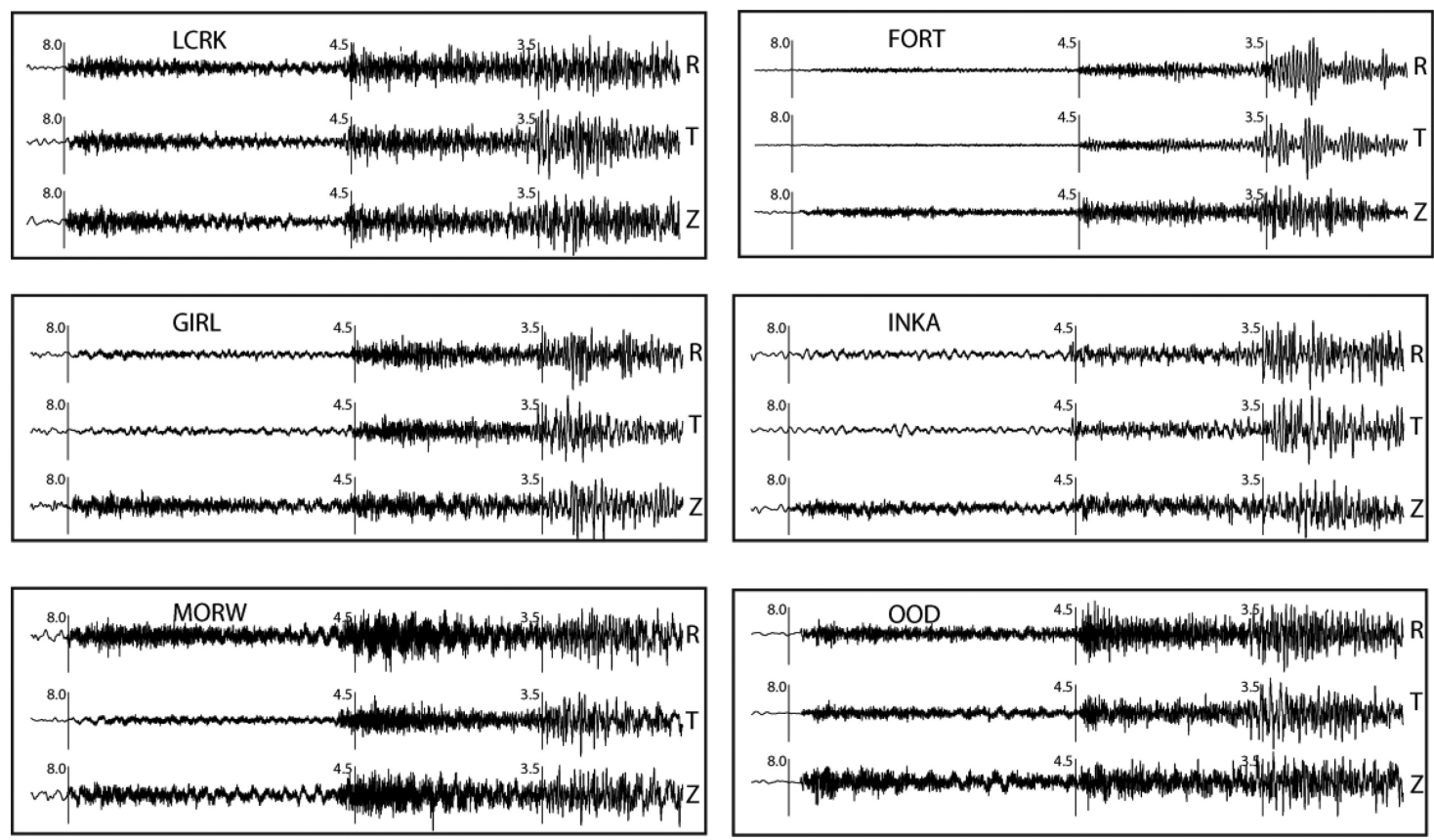

Figure 2. Selected three-component waveforms (radial—R; transverse-T; vertical—Z) for the $M_{\mathrm{b}} 4.8$ earthquake in Western Australia on 2016 November 6. The waveforms are drawn for the velocity window from 8.9 to $3.0 \mathrm{~km} \mathrm{~s}^{-1}$, with line markers at $8.0,4.5$ and $3.5 \mathrm{~km} \mathrm{~s}^{-1}$.

of paths for which the automatic picks work well. Other cases either deviate significantly from a visual assessment of the onsets, or are too sensitive to the parameter settings to be able to be applied across the different propagation regimes of the continent.

We have therefore developed a multicriterion tool to manipulate three-component records to pick both $P n$ and $S n$ arrivals based on both the energy and frequency distribution in the waveforms, as a function of time. Supporting Information Fig. S1 shows the details on how we pick the arrival times. To ensure the accuracy of the arrival picking, we eliminated data where the uncertainty in the pick is more than $1 \mathrm{~s}$ for $P n$ arrivals and $2 \mathrm{~s}$ for $S n$ arrivals. For the $S n$ arrivals, we mainly used the arrival times on transverse components, as they are usually clearer. The difficulties in picking $S n$ mean that it is not possible to make a systematic study of $S n$ splitting and hence $S$ anisotropy at the top of the mantle.

After relocation of events with a 3-D $P$ wave model, we discarded event-station pairs outside the distance range beyond $2^{\circ}$ to $15^{\circ}$, as well as event-station pairs that have $P n$ traveltime residuals larger than 8 s relative to the global ak135 model (Kennett et al. 1995). Negative $P n$ residuals can reach $-8 \mathrm{~s}$ at $15^{\circ}$ in central and western Australia (Sun \& Kennett 2016a). The $S n$ traveltime residuals relative to the ak135 model can reach twice those for $P n$ (from -16 to $16 \mathrm{~s}$ ). We did not employ stations with $S n$ traveltime residuals larger than $16 \mathrm{~s}$. With these criteria we have 303 events that occurred in Australia from 1994 to 2017 and 687 stations for the study of $S n$-wave velocity. Fig. 3 shows locations of these events and stations. There are only limited stations and events in the northeast of Australia, so the recovery of structure is weaker in this region.

Our final data set has $6068 P n$ picks and 5003 Sn picks. Fig. 4 shows the coverage of the $P n$ ray paths and $S n$ ray paths across the Australian continent after relocation of events using a 3-D $P$ model as in Sun \& Kennett (2016a). The paths of $P n$ and $S n$ waves are colour coded based on their traveltime residuals relative to the $a k 135$ model. Most of the $P n$ wave traveltimes lie in the range from -4 to 4 s. Whereas, the traveltime residuals of $S n$ wave mainly spread between -10 and $10 \mathrm{~s}$. Part of the difference in the span of the $P$ and $S$ residuals is a direct consequence of the lower velocity of $S$ waves, so that the same percentage change in wave speed produces a larger variation in absolute travel time than for $P$. It also appears that relative $S$-wave-speed variations in the lithosphere are larger than those for $P$.

The density of both $P n$ and $S n$ ray paths around the fringes of the continent are low. Crossing path density is relatively high for most of the continent, but somewhat lower in parts of Queensland and central Western Australia. The patterns of residuals show similar general patterns of apparent velocity for $P n$ and $S n$ waves. Both $S n$ and $P n$ waves at stations in the western Australia arrive systematically earlier than those at stations in the eastern Australia. In most parts of Australia, the $S$ wave speeds in the mantle are significantly faster than for ak135. Along the eastern fringes, the large positive traveltime residuals relative to ak135 indicate low apparent velocities in this region.

Fig. 4 displays the full range of ray paths, so that it can be difficult to assess the effect of the depth of penetration of $S n$ into the uppermost mantle. The zone immediately below the crust is sampled most strongly by short distance paths less than $6^{\circ}$. In Supporting Information Fig. S4, we show the patterns of ray paths for these short epicentral distances. Both $S n$ and $P n$ wave speeds are low in the uppermost mantle for parts of central Australia and the eastern margin of Australia, but high for the western part of Western Australia and the northern part of New South Wales.

\section{METHOD}

\subsection{Event relocation}

Since our estimates of the variations of seismic wave speed are dependent on the ray paths that we use between source and receiver, relocation of sources plays an important role in providing a more accurate velocity model. $P n$ arrivals can normally be picked 


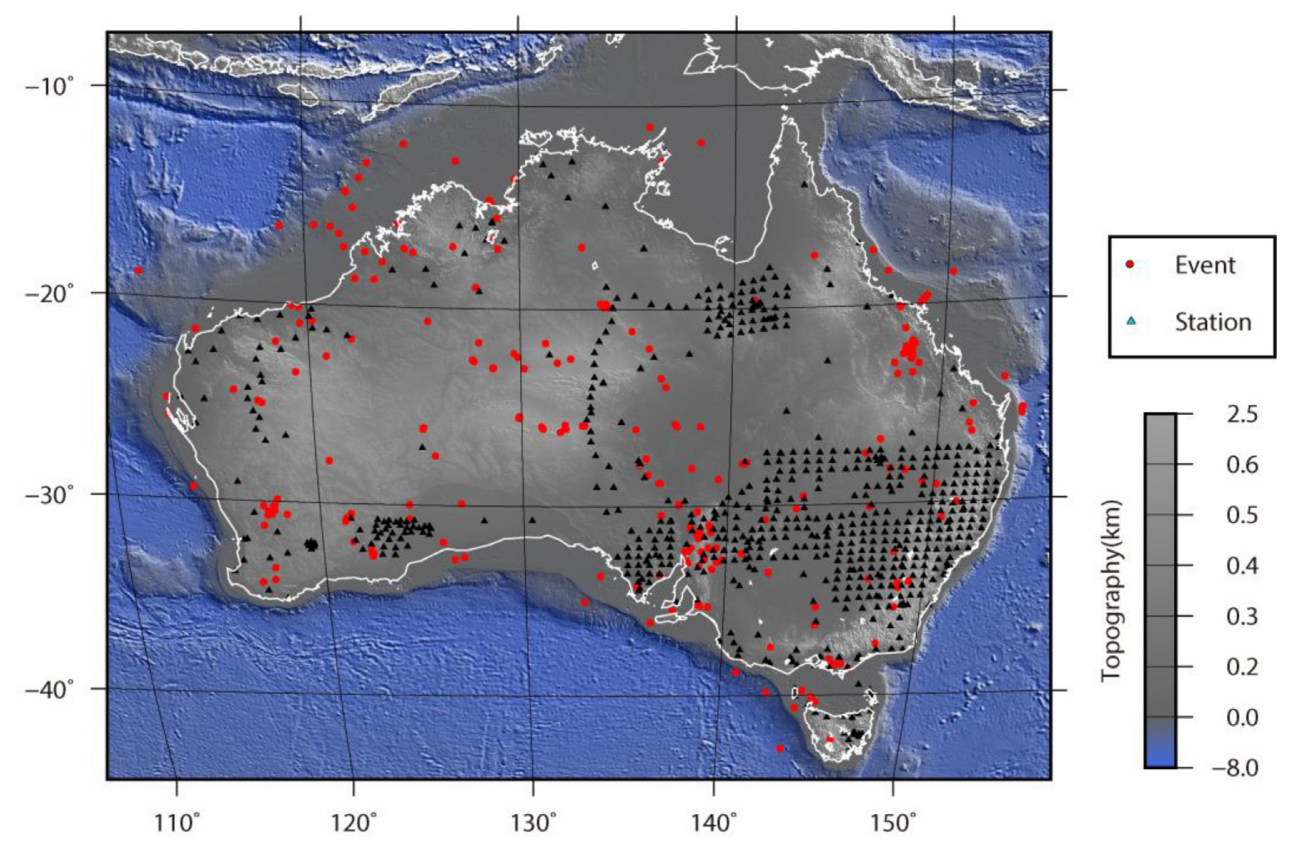

Figure 3. Map of the topography of the Australian region with the stations and events used in the study superimposed. Stations are represented by black triangles and events by red filled circles.
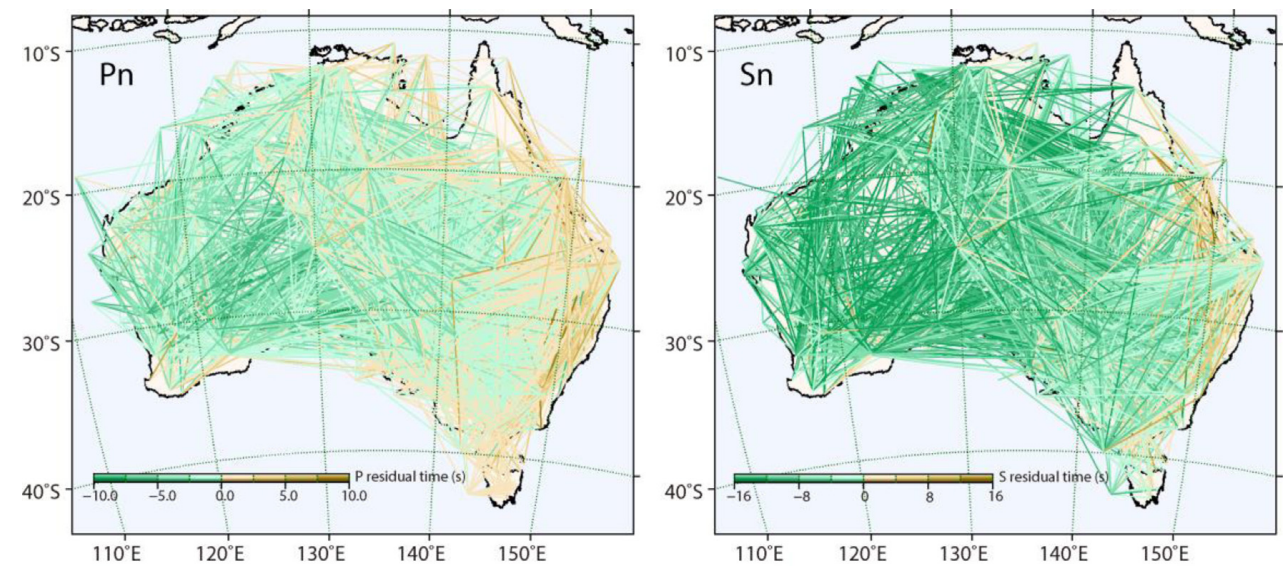

Figure 4. Ray path coverage for $P n$ and $S n$ after relocation. The paths are colour coded by the residuals relative to the ak135 model (Kennett et al. 1995).

with high accuracy, so we only use these arrivals to relocate the hypocentres and decide the origin times. We used the 3-D Pn-wavespeed model for the uppermost mantle developed by Sun \& Kennett (2016a) for relocation with a fully nonlinear 3-D scheme (de Kool $\&$ Kennett 2014) that has been demonstrated to be effective for continental scale relocation of hypocentres in Australia. This approach combines the multistage fast marching method (FMM; Rawlinson \& Sambridge 2005; de Kool et al. 2006) in spherical coordinates, used to compute the theoretical seismic traveltimes, with nonlinear search for the hypocentral parameters using the Neighbourhood Algorithm (Sambridge \& Kennett 2001). We excluded events that had more than $1^{\circ}$ location shifts from their initial positions.

The beneficial effects of the relocation procedure are apparent in the distribution of $P n$ traveltime residuals, as illustrated in the Supporting Information (Section S2). The original distribution of $P n$ traveltime residuals relative to the $a k 135$ model across the continent in Supporting Information Fig. S2(a) is disorganized, while Supporting Information Fig. S2(b) after relocation shows a much more consistent set of large-scale patterns of apparent velocity for
$P n$ across the whole continent. The changes are striking when we look at a single station. We consider FORT in the Eucla Basin; Supporting Information Fig. S3 shows the distribution of traveltime residuals relative to ak135. Before relocation, strong variations of traveltime residuals can be found for even close ray paths (Supporting Information Fig. S3a), but after relocation the patterns are consistent and generally faster than for ak135 (Supporting Information Fig. S3b). Histograms of the distribution of the residuals from ak135 before and after relocation demonstrate a tightening of the residual pattern and a shift in the median (Supporting Information Figs S3c and d).

With the corrected origin times for the events after 3-D relocation, we find that the average apparent $S n$ velocity for Australia is $4.70 \mathrm{~km}$ $\mathrm{s}^{-1}$ for Australia by conducting linear regression of the whole set of $S n$ traveltimes against epicentral distance. As noted above most of our readings are for $S H$ waves, but even so this is a rather high average wave speed. Such high $S n$ wave speeds for Australia were first noted by Huestis et al. (1973). 


\subsection{Sn tomographic inversion}

We have used the AuSREM model as the initial model for tomographic inversion of the $S n$ traveltimes for $S$ wave speed in the upper part of lithospheric mantle. This model provides a good description of the larger scale features of the 3-D structure beneath the Australian continent. We allow for modification of both crustal and mantle structure in the inversion, using the latest version of the depth to Moho to separate the crustal and mantle layers.

For inversion of the $P n$ times for 3-D $P$ structure, we started from the mantle $P$-wave velocity model from AuSREM. For both $P n$ and $S n$ we are able to make use of a good initial model, which helps to accelerate the progress of the inversion and produce a more reliable final model.

The region used for the wave-speed inversions spans from $110.5^{\circ} \mathrm{E}$ to $155.5^{\circ} \mathrm{E}$ and from $44.5^{\circ} \mathrm{S}$ to $10.0^{\circ} \mathrm{S}$, from the surface down to $180 \mathrm{~km}$ depth. We exploit the portion of the model down to $100 \mathrm{~km}$, since this has the best control from the $S n$ paths. The values of seismic velocities outside this region are taken directly from the AuSREM model. The wave speeds are represented on regular grids with grid intervals of $0.25^{\circ}$ in the horizontal directions and $10 \mathrm{~km}$ in depth for both crust and mantle.

The inversions of the $S n$ and $P n$ traveltimes are carried out with the FMTOMO scheme (Rawlinson \& Urvoy 2006) to produce 3-D velocity models. This procedure uses multistage FMM to predict traveltimes of $S n$ waves between stations and events. Then a subspace inversion scheme is used to modify the model parameters to minimize the error in the prediction of traveltimes over the whole inversion domain. After each iteration, the nonlinear FMTOMO method updates the full velocity model with a new calculation of $S n$ traveltimes. We have tried different damping and smoothing factors (Rawlinson \& Urvoy 2006), which range from 0.1 to 10 , in the inversion. From these trials, we have set both the damping factor and smoothing factor to 5 . These values enable us to avoid strong local anomalies and sharp changes, without missing important details in the velocity model.

As noted above, we included the crustal structure in the inversion. The initial crustal $S$ wave speed we used was from the AuSREM model, in which the crustal $S$ wave speed was built from the results of receiver functions as well as ambient noise studies (Salmon et al. 2013a). In this study, we could provide a new 3-D velocity model for the crustal part using the new inversion method and the data set of $S n$-wave traveltimes. The traveltimes of $S n$ waves are sensitive to crustal structure through their passage to and from the mantle in the neighbourhood of the sources and stations. The 3-D inversion using the $S n$ phase is therefore able to add more information on crustal structure, especially the constraints on the deeper part of the crust, which is somewhat quite patchy in the AuSREM crustal model (Salmon et al. 2013a).

\subsection{Resolution tests}

We have tested the recovery of $S$ wave structure in the FMTOMO inversion using the actual configuration of source and receiver pairs. Resolution tests were conducted using a checkerboard approach with variable grid sizes from $1.5^{\circ} \times 1.5^{\circ}$ to $4.5^{\circ} \times 4.5^{\circ}$ with a step of $1.5^{\circ}$. We used AuSREM as the initial model and added \pm 2 per cent checkerboard shaped perturbations at $60 \mathrm{~km}$ depth and \pm 1 per cent at $80 \mathrm{~km}$ depth to this model. We then generate a theoretical $S n$ traveltime data set and carry out an inversion of these results. The quality of the inversion is evaluated by the degree of the recovery of the original checkerboard patterns from the synthetic data.
Horizontal slices and vertical cross-sections for the perturbations imposed on the AuSREM model and the models recovered from the inversion are shown in Fig. 5. The recovery of structure is excellent in most parts of Australia. Even for the margins of the continent we still get reasonable recovery of the checkerboard patterns at $60 \mathrm{~km}$ depth, though ray paths are limited. Although the amplitudes of the patterns in central Western Australia are not recovered as fully as for the other regions, the shapes of these patterns are still similar to the original ones. At $80 \mathrm{~km}$ depth, we can still get quite good perturbations recovery that looks like the original patterns, although they are not as good as those at $60 \mathrm{~km}$ depth.

We illustrate comparable tests for the $P n$ data in the Supporting Information. Supporting Information Fig. S5 shows the recovery of checkerboard patterns on vertical slices and lateral slices for the $P n$-wave velocity model using the same $3.0^{\circ} \times 3.0^{\circ}$ pattern as for $\mathrm{Sn}$. With a slightly larger number of paths, we get somewhat better recovery of the checkerboard patterns for the $P n$-wave velocity tomography than for $S n$ (Fig. 5). The extra $P n$ ray paths tend to fill in the regions with weaker coverage for $S n$. The recovered checkerboard patterns for both $P n$ and $S n$ to the southeast of Canning Basin are not as clear as in other regions because there are only a limited number of crossing paths in this region. However, we can still find traces of the original patterns that we employed in the resolution test.

In Supporting Information Figs S6 and S7, we also show the checkerboard tests at 50 and $70 \mathrm{~km}$ depths. The recovery results are generally good for both $\mathrm{Sn}$ - and $P n$-wave velocity models across the whole continent when we use the $3.0^{\circ} \times 3.0^{\circ}$ checkerboard pattern. There may exist some upward smearing patterns, but they do not affect the main patterns severely, especially in the region deeper than $50 \mathrm{~km} . V_{\mathrm{p}} / V_{\mathrm{s}}$ ratios can be reliable when the resolution of the $S n$ - and $P n$-wave models are comparable. The resolution of $P n$-wave model is slightly better than $S n$ when we compare their resolutions at same depth. An area whose resolution is not good in $P n$-wave velocity model will also have poorer resolution in the $\mathrm{Sn}$ wave velocity model. The quality of the ratio results are thus mainly controlled by the $S n$-wave velocity model. Finally, we indicate the regions whose $V_{\mathrm{p}} / V_{\mathrm{s}}$ ratios may not reliable based on the resolution of the $S n$-wave velocity model.

To supplement the checkerboard tests we have made hypothesis tests for both $P n$ - and $S n$-wave velocity tomography to examine the recovery of high and low velocity features. We have added a number of circular perturbations of radius $3^{\circ}$ with amplitudes of \pm 2 per cent centred at $50 \mathrm{~km}$ to the initial models that we used to invert for the 3-D $S$ - and $P$-wave velocity model. Once again, we construct synthetic traveltime data for $P n$ and $S n$ and invert for 3-D structure. Supporting Information Fig. S8 shows the pattern of the features and their recovery. The red perturbations with lowered wave speeds were added in regions that have low velocity, while the blue circles were imposed on high velocity regions. The degree of recovery of these additional features is good, especially for $\mathrm{Pn}$ tomography.

To test the reliability of the 3-D $V_{\mathrm{p}} / V_{\mathrm{s}}$ model, we perform a resolution test for the $V_{\mathrm{p}} / V_{\mathrm{s}}$ ratio based on the $V_{\mathrm{p}}$ and $V_{\mathrm{s}}$ models from the inversion. Supporting Information Fig. S9 shows the results at 60 and $80 \mathrm{~km}$ depths. The behaviour is similar to the patterns shown in Fig. 5. The recovery at $60 \mathrm{~km}$ is quite good across most of the continent, though it is rather weak in the desert regions of central Western Australia. The well-recovered checkerboard pattern at $80 \mathrm{~km}$ depth indicates that we can still get valid $V_{\mathrm{p}} / V_{\mathrm{s}}$ information at such deeper depths. 

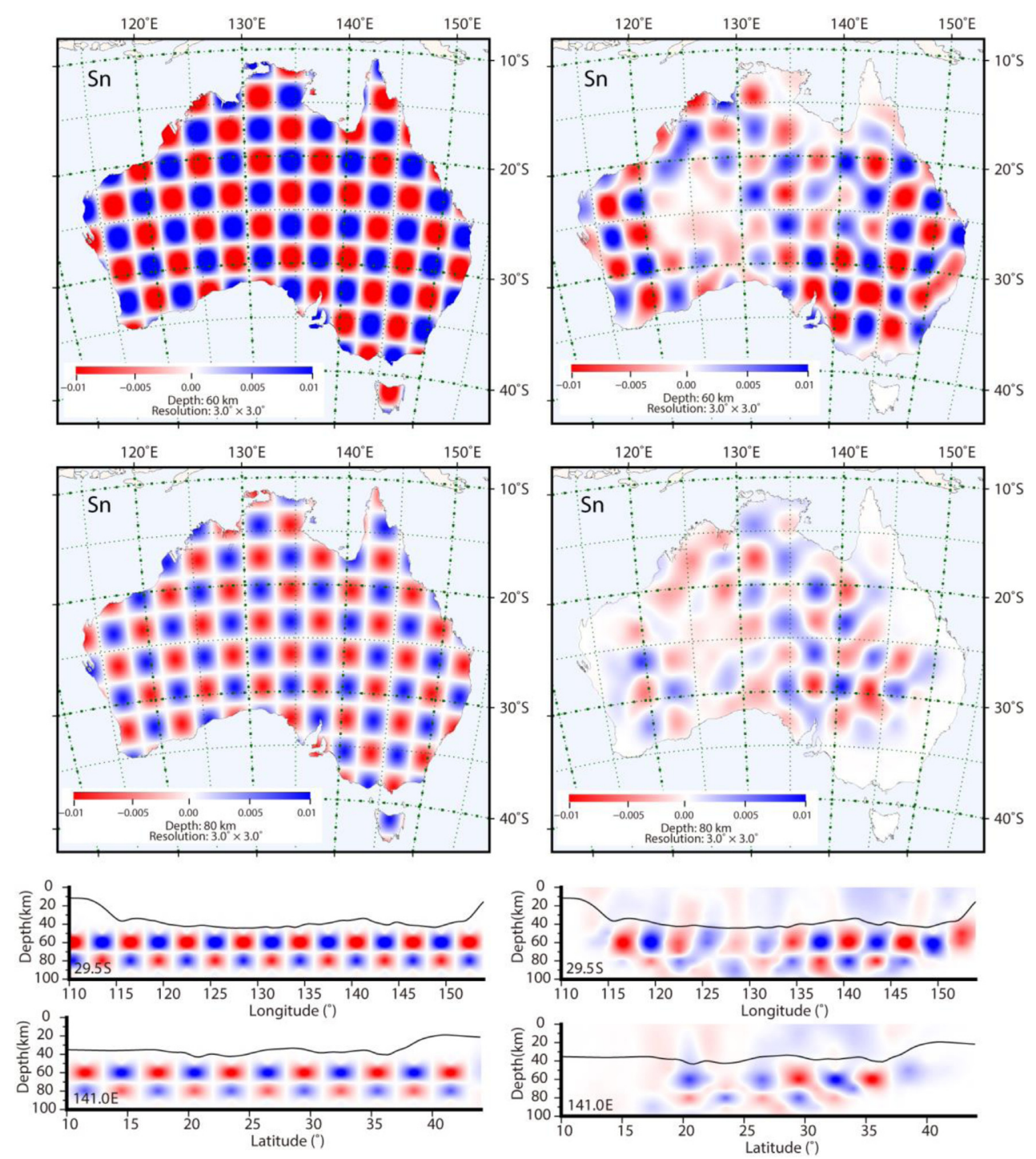

Figure 5. Resolution test for the $S n$-wave velocity model. The horizontal slices show the original and recovered patterns at 60 and $80 \mathrm{~km}$ depths, and the vertical sections show the patterns along the longitude $141.0^{\circ}$ and latitude $-29.5^{\circ}$. The size of the checkerboard is $3.0^{\circ} \times 3.0^{\circ}$. The colour bar shows the size of velocity perturbation. The black lines indicate the depth of the Moho.

\section{RESULTS}

\subsection{Sn-wave-speed distribution}

We achieved rapid convergence of the inversion for the $S$-wave velocity model for the whole Australian continent from the $S n$ traveltimes, in part because we were able to employ a good initial model, which contained most of the major patterns of variation in wave speed. The minimum misfit was achieved after just three iterations. The root mean square traveltime residual for $S n$ was reduced from the initial value of 4.171 to $2.792 \mathrm{~s}$, a final variance reduction of 55 per cent.

We focus attention on the results for the $S$ velocity below $50 \mathrm{~km}$ to study the characteristics of the uppermost mantle, which is the least constrained portion of the AuSREM model. Fig. 6 shows maps for our new $S n$ velocity model at depths of 50, 60, 70 and $80 \mathrm{~km}$, the comparable depth slices for the AuSREM model are shown in Supporting Information Fig. S10. In each case, we display the absolute velocity values across the Australian continent with the same colour scale for the velocity range from 4.0 to $5.0 \mathrm{~km} \mathrm{~s}^{-1}$.
A feature of the $S$ velocity distribution derived from the $S n$ inversion (Fig. 6) is patchiness in the wave-speed distribution, compared with the smoother, but distinct, variations in AuSREM. Most parts of Australia are characterized by relatively high $S n$-wave velocities though central Australia shows patches of low wave speed, below $4.5 \mathrm{~km} \mathrm{~s}^{-1}$. The eastern Australia margin also has rather low mantle $S$ velocities in some places. We are able to confirm the reliability of these features by examining the characteristics of short ray paths (Supporting Information Fig. S4); the central region and eastern Australian margin show significant positive residuals relative to ak135. The highest $S n$ velocity of $4.94 \mathrm{~km} \mathrm{~s}^{-1}$ lies in Western Australia. The lowest-velocity zone is located between $20^{\circ} \mathrm{S}$ and $25^{\circ} \mathrm{S}$ in eastern Queensland.

The variations of the vertical gradient of $S$-wave speed in the uppermost mantle across Australia are complex. We display crosssections down to $100 \mathrm{~km}$ at constant longitude in Fig. 7 and constant latitude in Fig. 8. Compared with the $S$-wave speed patterns in the crust, those in the uppermost mantle are rather heterogeneous. Many of the locally highest $S$-wave speed features are located at around 

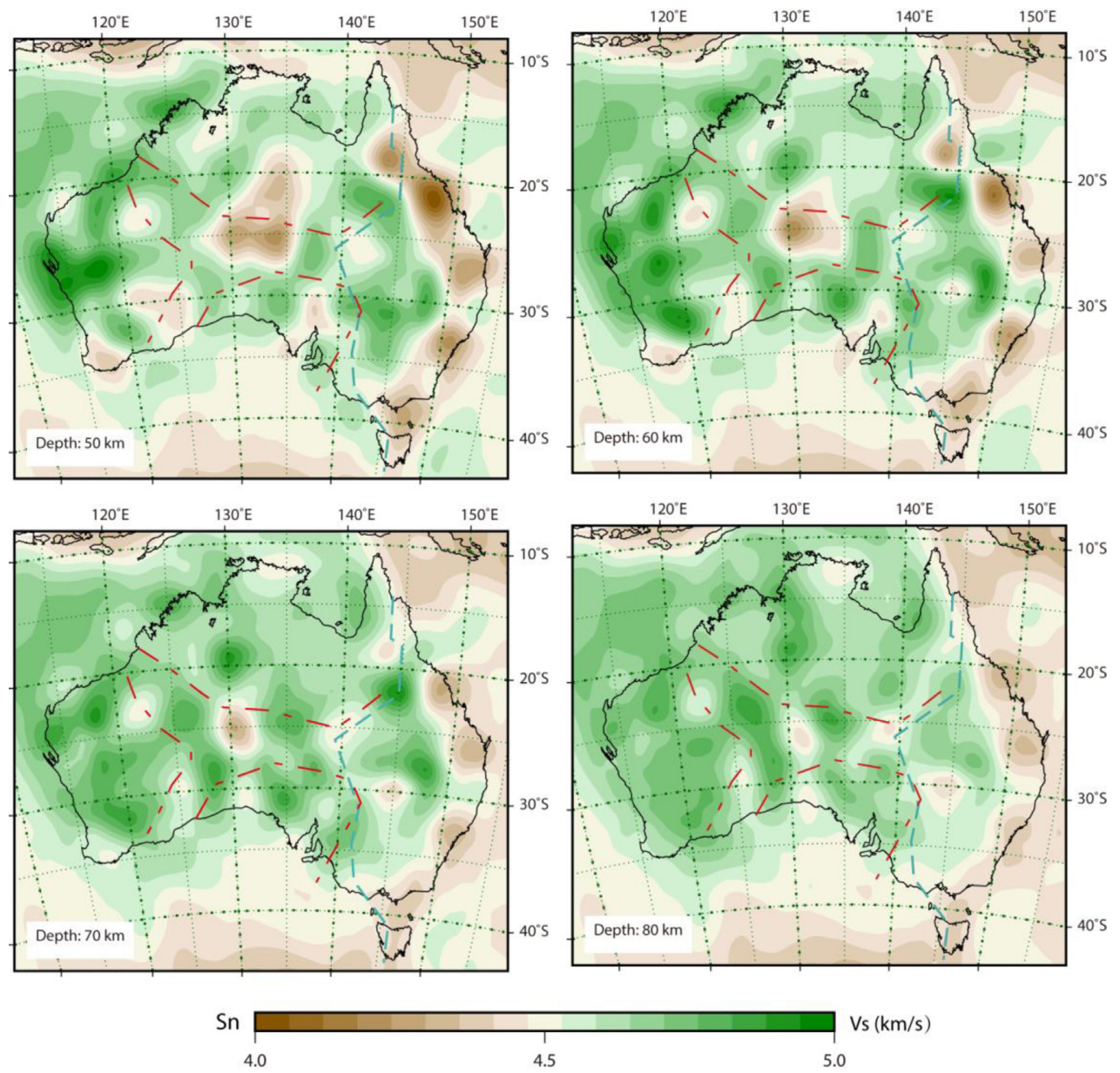

Figure 6. $S n$-wave velocities across Australia for depth slices from 50 to $80 \mathrm{~km}$ depth with a step of $10 \mathrm{~km}$. The red dashed lines are craton boundaries. The light blue dashed line represents the Tasman Line.

$65 \mathrm{~km}$ depth. The fastest-velocity anomalies in Western Australia usually have shallower depths, for instance along the $120^{\circ} \mathrm{E}$ profile the highest velocities are located slightly above $60 \mathrm{~km}$. For the $145^{\circ} \mathrm{E}$ profile in Fig. 7, the fast anomaly centred at about $65 \mathrm{~km}$ between $20^{\circ} \mathrm{S}$ and $25^{\circ} \mathrm{S}$ beneath the northeastern Eromanga basin stretches nearly horizontally. Another fast-wave-speed zone $\left(>4.8 \mathrm{~km} \mathrm{~s}^{-1}\right)$, at $20^{\circ} \mathrm{S}, 130^{\circ} \mathrm{E}$ close to $70 \mathrm{~km}$ depth, extends both upwards and downwards. High-wave speed patches located at greater depths are also present. For example, along the $25^{\circ} \mathrm{S}$ profiles, the complex structures in central Australia show a slow-velocity region surrounded by two high-velocity zones whose highest-wave speeds are located below $75 \mathrm{~km}$, the two features extend obliquely downwards to meet each other.

The 3-D $S$-wave-speed model produced by the inversion of the $S n$ traveltime picks has stronger spatial wave speed variations for the initial AuSREM model that represents long-wavelength behaviour, though the general patterns of $S$-wave speed are similar. The $S n$ paths provide much finer, though uneven, sampling across the continent allowing the recovery of smaller scale features in the lithosphere. The variability of $S$ wave speed indicates the presence of significant substructure, much of which appears to tie to different crustal blocks.

We have inverted for 3-D $P$ - and $S$-wave velocity model independently from the $P n$ and $S n$ data sets. We used $6049 P n$ ray paths between 316 events and 687 stations for the inversion of the 3-D $P$ wave velocity model. The final 3-D $P$ model shows general patterns that is similar to the initial model. The $P$ model is presented in Supporting Information Fig. S11 with depth slices at depths from 50, 60,70 and $80 \mathrm{~km}$. The $P$-wave velocity patterns also show strong local variations in a similar way to our $S$ velocity model.

\section{2 $V_{\mathrm{p}} / V_{\mathrm{s}}$ ratio distribution}

We have used trilinear interpolation to extract the values of $S$ and $P$ wave speed from the $3-\mathrm{D}$ models at the same location, so as to produce a 3-D model for the $V_{\mathrm{p}} / V_{\mathrm{s}}$ ratio. In Fig. 9, we illustrate the $V_{\mathrm{p}} / V_{\mathrm{s}}$ ratio for depths of $50,60,70$ and $80 \mathrm{~km}$. The transparent grey shapes indicate regions whose resolutions are not as good as that of the other regions on the maps. There are significant variations in the $V_{\mathrm{p}} / V_{\mathrm{s}}$ across continent with most of values ranging from 1.65 to 1.85 in the uppermost mantle. Localized effects of thick crust influence the map at $50 \mathrm{~km}$. The most distinctive feature of the $V_{\mathrm{p}} / V_{\mathrm{s}}$ distribution is the central high values, which extends to a depth of nearly $80 \mathrm{~km}$ at the centre of Australian continent. The pattern of the $V_{\mathrm{p}} / V_{\mathrm{s}}$ ratio in eastern Australia is generally more complex than in the western part of Australia.

We show cross-sections through the $3-\mathrm{D} V_{\mathrm{p}} / V_{\mathrm{s}}$ model in Fig. 10 at $8^{\circ}$ intervals in longitude and $5^{\circ}$ in latitude. There is a distinct difference between the $V_{\mathrm{p}} / V_{\mathrm{s}}$ ratios in the crust and uppermost mantle. Much of the Australian crust has low ratio values, though there are some isolated patches of higher ratios. Generally, the $V_{\mathrm{p}} / V_{\mathrm{s}}$ 

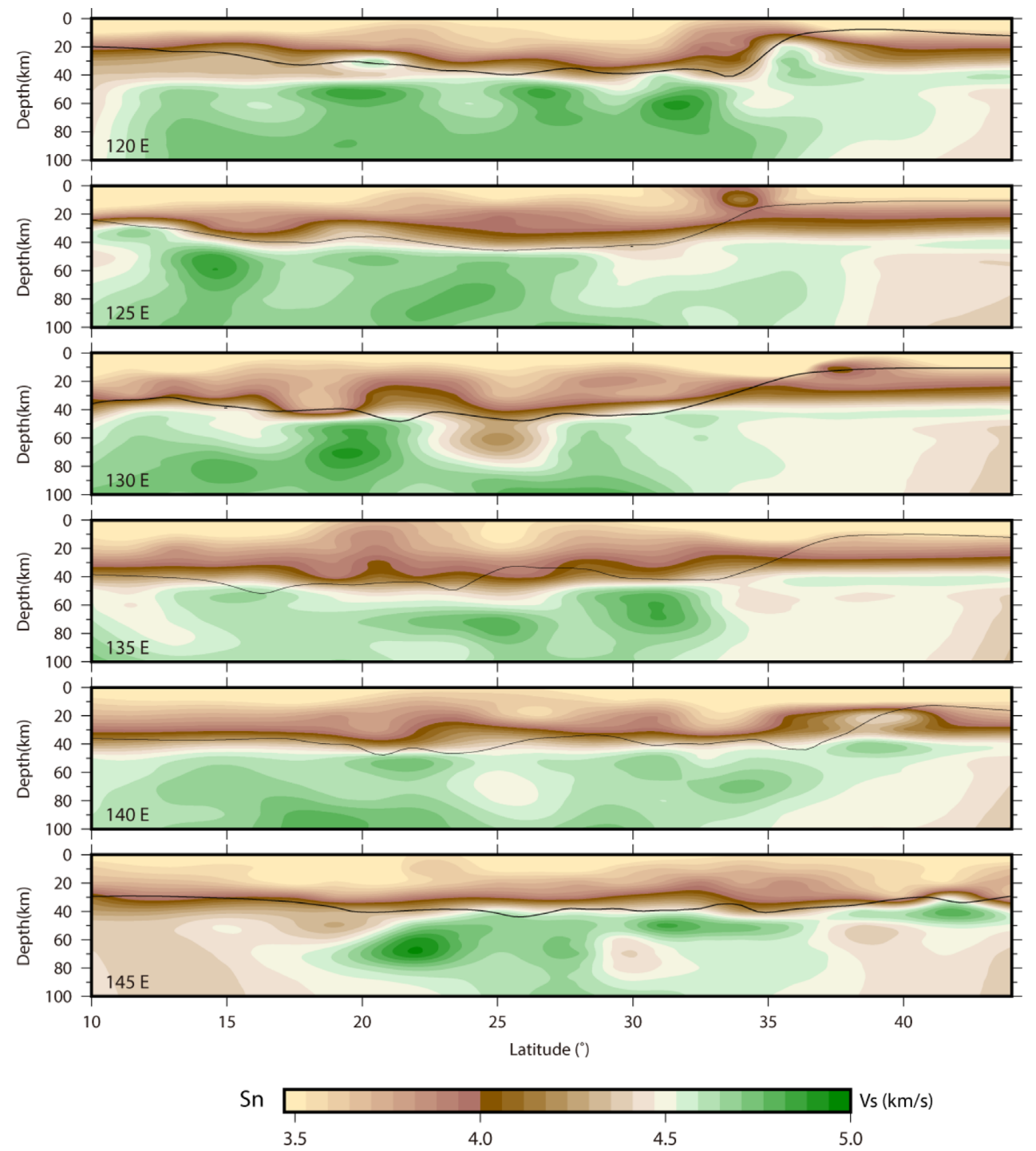

Figure 7. $\mathrm{Sn}$-wave velocities for cross-sections across Australia at constant longitude from $120^{\circ} \mathrm{E}$ to $145^{\circ} \mathrm{E}$ with a step of $5^{\circ}$.

ratio in the uppermost mantle is higher than that of crust and the highest $V_{\mathrm{p}} / V_{\mathrm{s}}$ ratios are usually located just below the Moho.

\section{DISCUSSION}

\subsection{Complex 3-DSn-wave-speed structures beneath different geological provinces}

As we can see from Fig. 4, Australia is mainly characterized by fast $S n$-wave speeds, especially for Western Australia. The fastest $S$ velocities in the uppermost mantle are found in the Archean Yilgarn and Pilbara Cratons (Fig. 1), above $4.9 \mathrm{~km} \mathrm{~s}^{-1}$. Along $120^{\circ} \mathrm{E}$ in the continental zone between $20^{\circ} \mathrm{S}$ and $35^{\circ} \mathrm{S}$ (Fig. 7), there are three zones of high wave speed located between 50 and $60 \mathrm{~km}$ depths. A high velocity zone extends from north to south beneath Pilbara Block, while two separated fast zones occur beneath the Yilgarn Craton. Below $80 \mathrm{~km}$ depth, the local very high velocities disappear and a rather homogeneous distribution of velocity emerges. Huestis et al. (1973) noted apparent $S n$-wave velocities ranging from 4.75$4.87 \mathrm{~km} \mathrm{~s}^{-1}$ for western Australia, which is consistent with our results and the absence of tectonic activity since around $1200 \mathrm{Ma}$.
The average $S$ velocity beneath the North Australian Craton between 50 and $100 \mathrm{~km}$ depths is about $4.7 \mathrm{~km} \mathrm{~s}^{-1}$, with a local high velocity anomaly to the northwest of the Kimberley Block. In central Australia, a remarkable localized zone of lowered $S$ velocities (lower than $4.4 \mathrm{~km} \mathrm{~s}^{-1}$ ) matches with the location of low wave speeds for $P$ (Supporting Information Fig. S11). The feature is more concentrated than in the initial AuSREM model (Supporting Information Fig. S10). This area has thick crust, as can be seen in the Moho map in Fig. 1, updated from Salmon et al. (2013b). However, we generally find modest influence from crustal thickness on the $S$-wave speed in the uppermost mantle. For example, the area in the middle of McArthur basin, has thick crust, but is characterized by high $S$ velocities between depths of 50 and $80 \mathrm{~km}$. Between the Eucla Basin, the South Australia Craton and the Officer Basin, a slightly slower velocity region (lower than $4.6 \mathrm{~km} \mathrm{~s}^{-1}$ ) compared with the average velocity extends below the depth of $80 \mathrm{~km}$.

$S$-wave speed variations in the Eromanga Basin are rather weak between 40 and $90 \mathrm{~km}$, as can be seen on the $140^{\circ} \mathrm{E}$ slice in Fig. 7. Beneath eastern Australia, the low $S$ velocity strip along the coastline links to the thinner lithosphere along the margin noted by Davies et al. (2015). 

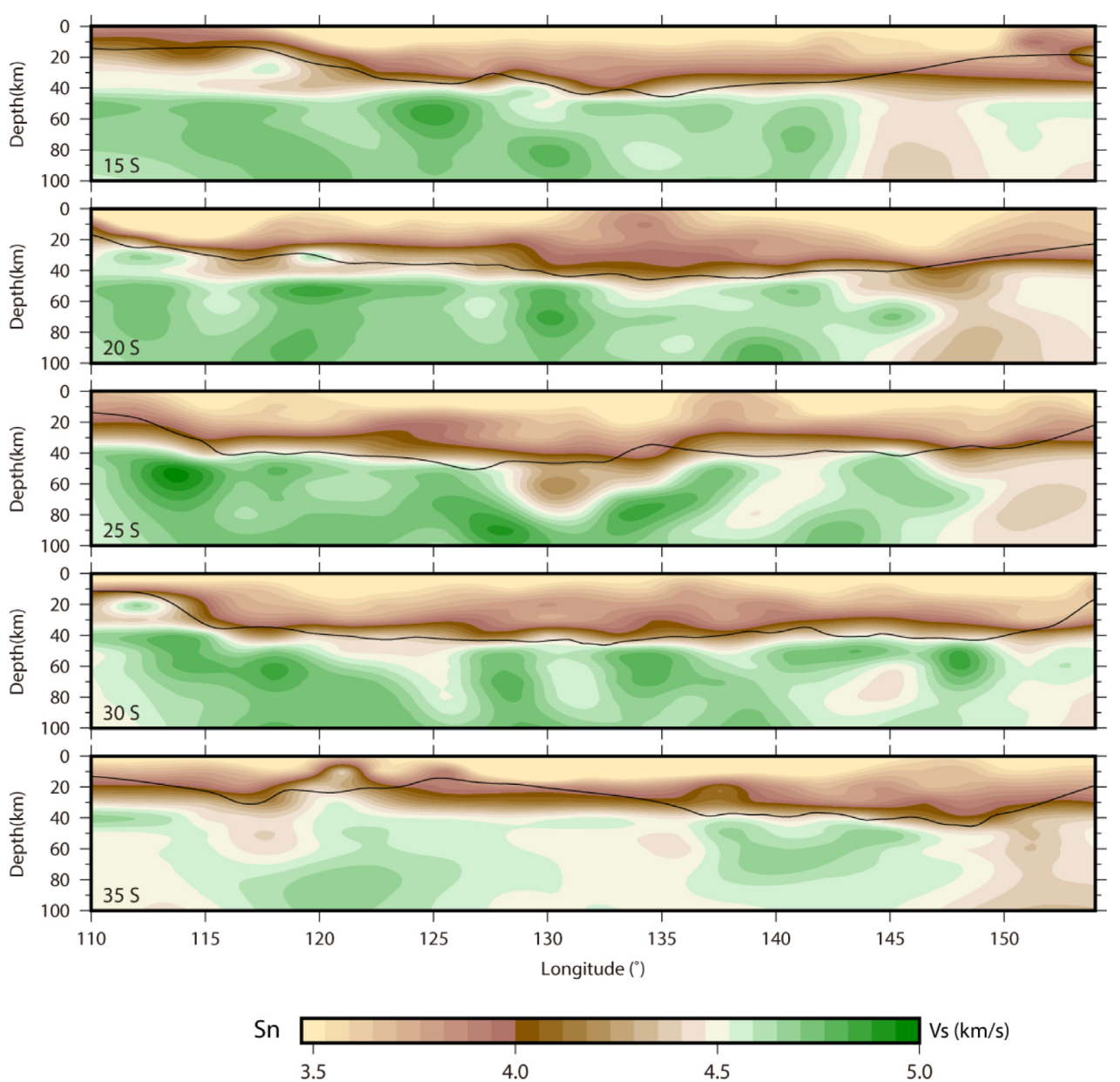

Figure 8. $\mathrm{Sn}$-wave velocities for cross-sections across Australia at constant latitude from $15^{\circ} \mathrm{S}$ to $35^{\circ} \mathrm{S}$ with a step of $5^{\circ}$.

For the section through Central Australia along $130^{\circ} \mathrm{E}$, we find that the variation of $S$-wave velocity is closely related to the age of the blocks along this longitude with distinct low velocities for the Amadeus Basin and the zones affected by the Alice Springs orogeny that terminated at around $300 \mathrm{Ma}$. Along $135^{\circ} \mathrm{E}$, the Gawler Craton has a large fast wave speed zone between 50 and $80 \mathrm{~km}$ depths. On the profile along $140^{\circ} \mathrm{E}$, which mainly crosses Phanerozoic regions, $S$ velocities are just slightly higher than $4.5 \mathrm{~km} \mathrm{~s}^{-1}$. Thus stable regions usually have high values for $S n$ wave speed.

Unlike the crust, the uppermost mantle does not have any consistent trend of increase in $S$ velocity with depth. Instead, we find geographically variable behaviour likely to have been imposed by the tectonic history. In Fig. 1, we indicate the Tasman Line based on the work of Direen \& Crawford (2003), which represents the eastern extension of Precambrian material in the crust. There is no direct relation of the Tasman Line with the variations in $S$-wave velocity variation in the uppermost mantle.

\subsection{Fast average $S n$-wave speed}

Across Australia, areas of low $S n$ wave speed are limited and most parts of the uppermost mantle are characterized by velocities above $4.5 \mathrm{~km} \mathrm{~s}^{-1}$. Indeed the average apparent $S n$ wave speed for the paths across the whole Australian continent is $4.70 \mathrm{~km} \mathrm{~s}^{-1}$, which is quite high as compared with other continents. Díaz et al. (2012) obtained $4.60 \mathrm{~km} \mathrm{~s}^{-1}$ for the mean $S n$ wave speed across the EuroMediterranean region. Pei et al. (2004) reported an average $S n$ velocity of $4.55 \mathrm{~km} \mathrm{~s}^{-1}$ for the whole continental region of China. The western United States has average $S n$ velocity of $4.29 \mathrm{~km} \mathrm{~s}^{-1}$ (Goes \& van der Lee 2002).

\subsection{High correlation between $S n$ - and $P n$-wave-speed structures}

The $S n$ tomographic images provide independent confirmation of most of the features revealed by $P n$ tomography (Supporting Information Fig. S11). The regions with high $P$-wave speed usually also have high $S$-wave speed. Consider, for example, the $S$ and $P$ velocities at $60 \mathrm{~km}$ depth. The West Australian Craton, a large part of eastern Australia and the South Australian Craton and the northern part of North Australian Craton are generally characterized by high velocities for both $S n$ and $P n$ phases, particularly the Yilgarn Craton where $S n$ velocity is near to $5.0 \mathrm{~km} \mathrm{~s}^{-1}$ and $P n$ is near to $8.5 \mathrm{~km}$ $\mathrm{s}^{-1}$. Regions with lower $S n$ - and $P n$-wave speed can be found in the Kimberley Basin as well as central Australia. There are some regions indicated by rather low $S n$ and $P n$-wave speed, such as areas along eastern Australia margin where $S n$ and $P n$ velocities are below 4.0 and $7.5 \mathrm{~km} \mathrm{~s}^{-1}$ at $50 \mathrm{~km}$ depth, respectively. 

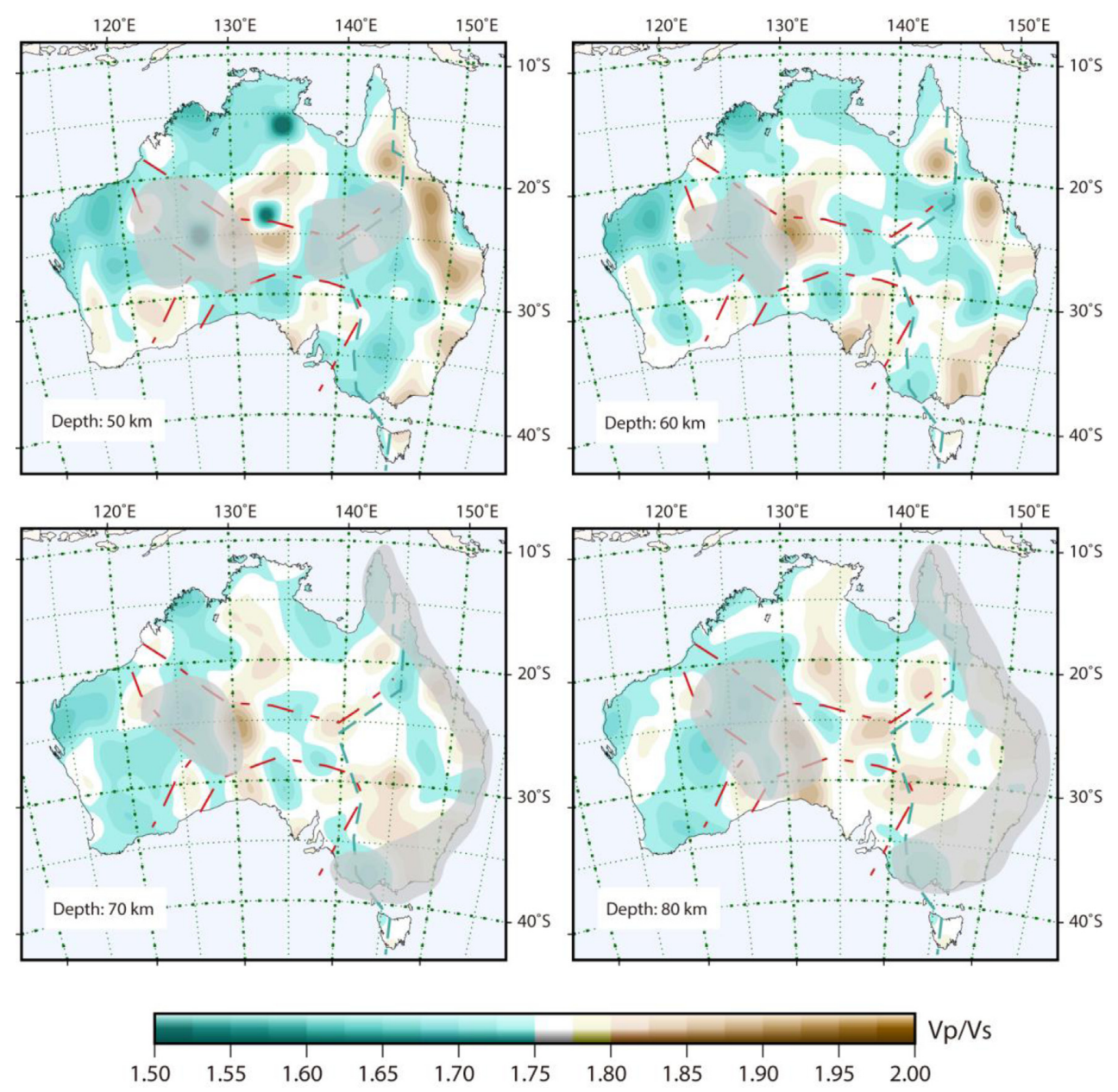

Figure 9. Maps of the $V_{\mathrm{p}} / V_{\mathrm{s}}$ ratio across Australia for depth slices from 50 to $80 \mathrm{~km}$ depths with a step of $10 \mathrm{~km}$. The transparent grey patterns on the maps show regions that may be not reliable. The red dashed lines are craton boundaries. The light blue dashed line represents the Tasman Line.

\section{$5.4 V_{\mathrm{p}} / V_{\mathrm{s}}$ values for different regions}

The general consistency of the $P$ and $S$ velocities in the uppermost mantle results in somewhat muted variations in the $V_{\mathrm{p}} / V_{\mathrm{s}}$ ratio in Figs 9 and 10. Though there are sharp changes near the Moho interface (Fig. 10), with an increase in the $V_{\mathrm{p}} / V_{\mathrm{s}}$ ratio in the uppermost mantle. Similar results were found by Shibutani et al. (1996) and Clitheroe et al. (2000) in receiver function studies of the crust and uppermost mantle structure beneath the Australian continent.

Within the uppermost mantle, parts of some basins with thick sedimentary deposits, such as the Canning Basin, Amadeus Basin and Eromanga Basin, are well imaged with a large $V_{\mathrm{p}} / V_{\mathrm{s}}$ ratio (Fig. 9). Higher $V_{\mathrm{p}} / V_{\mathrm{s}}$ ratios are seen in the southwest Canning Basin, with an increasing size of the feature and larger values extending from shallow depth down to $80 \mathrm{~km}$. The $V_{\mathrm{p}} / V_{\mathrm{s}}$ ratio is generally low in the western part of Australia with notable contrasts between the western part and middle part of Australia, although the patterns become more variable with increasing depth. Much of central Australia is dominated by high $V_{\mathrm{p}} / V_{\mathrm{s}}$ values. They keep changing in all directions with increase of the depth from $60 \mathrm{~km}$ to $80 \mathrm{~km}$. The highest $V_{\mathrm{p}} / V_{\mathrm{s}}$ ratio is linked to the Arunta Block, Amadeus Basin and Musgrave Block between 40 and $90 \mathrm{~km}$ depths.

\subsection{Regional anomalies revealed by both $S n$-wave speeds and $V_{\mathrm{p}} / V_{\mathrm{s}}$ values}

The New England Orogen and Lachlan Fold Belt along the eastern continental margins have relatively high $V_{\mathrm{p}} / V_{\mathrm{s}}$ values at $50 \mathrm{~km}$ depth, which tend to diminish with depth. Tasmania is not adequately resolved with the available data. Apart from the margin, eastern Australia is generally characterized by high $S n$ and $P n$ wave speed in the uppermost mantle. The eastern margin has a number of age-progressive chains of dormant volcanoes that are formed as the Australian continent drifted north-northeast over some mantle plume traces (Davies et al. 2015). Five substructures along the margin with high $V_{\mathrm{p}} / V_{\mathrm{s}}$ anomalies can be found at depths extending from $50 \mathrm{~km}$ to below $60 \mathrm{~km}$ (Fig. 9) and are generally consistent with the low $S n$-wave speed anomalies revealed in this study (Fig. 6). Although the eastern margin does not have particularly good resolution for depths greater than $60 \mathrm{~km}$, we can still find some high $V_{\mathrm{p}} / V_{\mathrm{s}}$ patterns relative to these five high anomaly zones on the maps at 70 and $80 \mathrm{~km}$ depths. These features link to the location of some of the volcanoes on the eastern margin. The low velocities in the northern parts of the strip appear to relate to volcanism that extended until 11 $000 \mathrm{yr}$ ago (Johnson et al. 1989). The southeastern low $V_{\mathrm{s}}$ features in the Lachlan orogen can also be linked to volcanic activity lasting until $4000 \mathrm{yr}$ ago. Combined with the high $V_{\mathrm{p}} / V_{\mathrm{s}}$ ratios, the low $S n$-wave speed suggests that there could be near-melt conditions beneath these features. In Fig. 8, we can clearly see some low $S n$-wave 

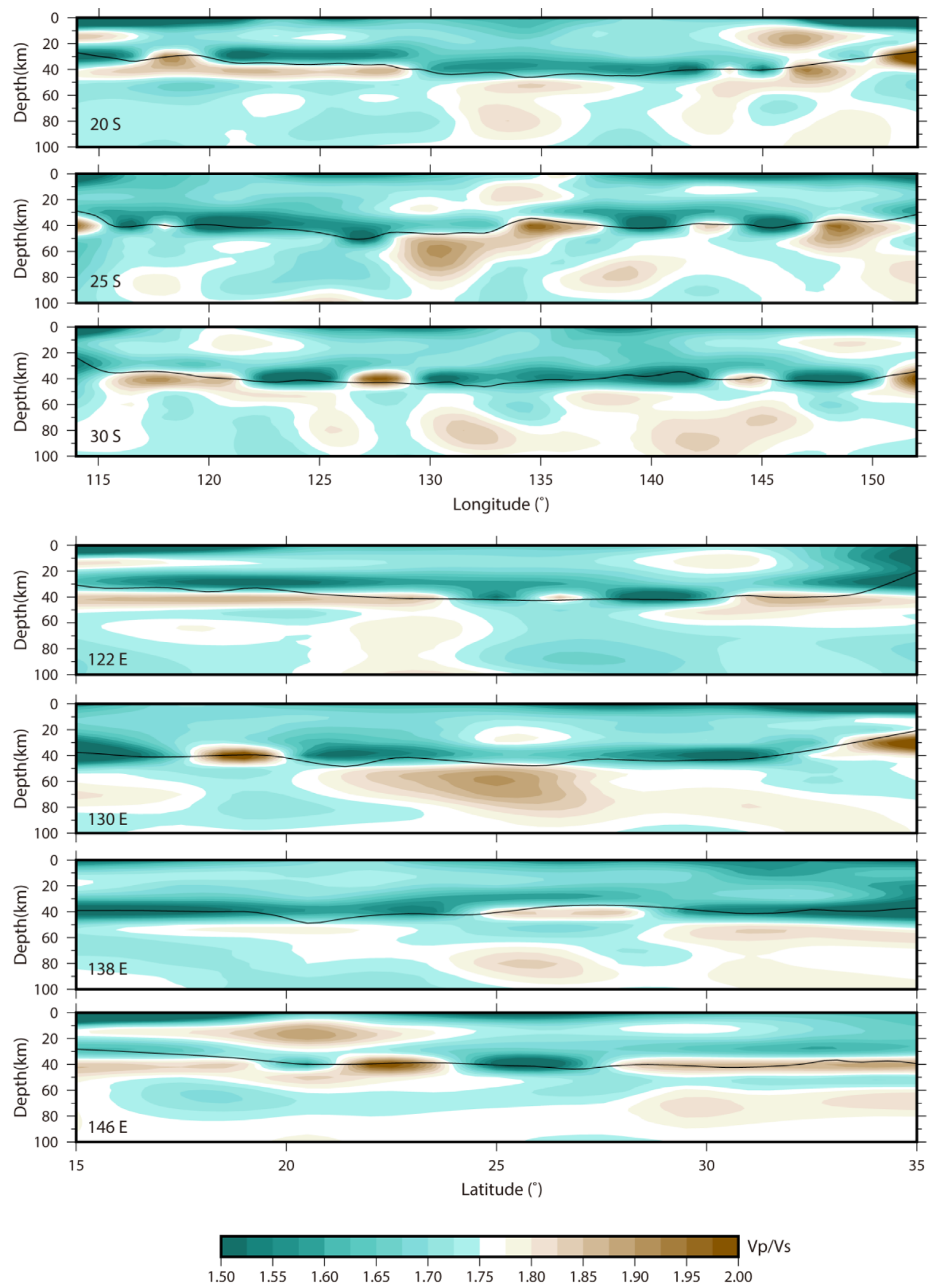

Figure 10. Cross-sections of the $V_{\mathrm{p}} / V_{\mathrm{s}}$ ratio across Australia along $20^{\circ} \mathrm{S}-30^{\circ} \mathrm{S}$ with a step of $5^{\circ}$ and $122^{\circ} \mathrm{E}-146^{\circ} \mathrm{E}$ with a step of $8^{\circ}$.

velocity channels in the uppermost mantle along $15^{\circ} \mathrm{S}, 20^{\circ} \mathrm{S}$ and $35^{\circ} \mathrm{S}$. The five anomalies may indicate remnants of the influence of mantle plumes on the uppermost mantle along the margin.

In the uppermost mantle of central Australia, a region dominated by low seismic wave speeds at approximately $75 \mathrm{~km}$ depth has been found in surface-wave based studies (Fishwick \& Reading 2008;
Fishwick \& Rawlinson 2012). The AuSREM model also shows low $S$-wave velocity for this region. It would appear that a localized zone may have been smeared out when imaged with the long-wavelength surface waves.

The low $S$ velocities beneath the Arunta Block, Amadeus Basin and Musgrave Block extend down to $80 \mathrm{~km}$, beneath crust with 
rather variable thickness (Fig. 1). It is hard to explain the shallow low-velocity structure, and strong positive wave-speed gradient in terms of typical steady-state continental geotherms in the uppermost mantle. This region is indeed associated with rather high heat flow (Cull 1982), but this is likely to come from the high heat production of the crust, rather than from the mantle (McLaren et al. 2003). A thermal explanation of the low velocities in the uppermost mantle needs to redistribute the elements that can produce high heat within the crust to the mantle (Fishwick \& Reading 2008). Relatively low seismic body-wave attenuation in this region makes velocity reduction by partial melting rather unlikely. Fishwick \& Reading (2008) have suggested that minerals with low seismic velocities in the shallowest part of the lithosphere, with a more conventional lithology in the deep continental root below, could explain the seismic velocities.

Shear wave speed is sensitive to the presence of areas with locally higher temperature, partial melt and tectonic activities. The corner between Queensland and South Australia in the Eromanga basin has slower $S n$-wave velocity (around $4.5 \mathrm{~km} \mathrm{~s}^{-1}$ ) compared with its surrounding regions. The zone is also defined by strong $V_{\mathrm{p}} / V_{\mathrm{s}}$ ratios with values larger than 1.8 , as well as local high geotherms and high attenuation of seismic waves in the crust (Wei et al. 2017). Variations in temperature are thus expected to play a major role in controlling the velocity pattern in this area.

The Canning basin and the Capricorn Orogen are generally defined by high $S$-wave velocity. But we find local slight anomalies in the uppermost mantle for the $V_{\mathrm{p}} / V_{\mathrm{s}}$ ratio and $S$ wave speed in the region located between the southwestern part of Canning basin and the northeastern part of the Capricorn Orogen. In the same area, we also find slightly lower $P n$ velocities extending from 50 to $60 \mathrm{~km}$ (Supporting Information Fig. S11). This region is a transition zone between high and low seismic wave attenuation, thin to thick crust and high to low geotherms in the crust. A patch of lower $S$ wave speed around $130^{\circ} \mathrm{E}, 25^{\circ} \mathrm{S}$ persists below $80 \mathrm{~km}$ depth (Figs 7 and 8), bordering the rather high $S n$ and $P n$ velocities of the Western Australian cratons.

\section{CONCLUSIONS}

The tomographic inversion of over 5000 arrival times of manually picked $S n$ waves, has been used to produce a 3-D $S$-wave velocity model with spatial resolution of $3.0^{\circ} \times 3.0^{\circ}$. The $S$-wave speed model provides valuable Supporting Information on the uppermost mantle and further insights into the features of different geology blocks in Australia. The initial AuSREM model, which provides a good representation of the large-scale velocity features of the Australian lithosphere, helped us to get rapid convergence of the nonlinear tomographic inversion. We are able to extract smallerscale structures for the $S$-wave-speed distribution in 3-D, such as the local high-velocity substructures beneath the Pilbara and Yilgarn cratons. The pattern of $S n$-wave velocities in the uppermost mantle below the Australian continent is rather complex and indicates the presence of substructure within major units such as the cratons. We have compared the $S$-wave-speed distribution with that for $P$ waves obtained by a similar tomographic inversion of $P n$ picks. On the eastern margin, low $S$ wave speed and high $V_{\mathrm{p}} / V_{\mathrm{s}}$ ratio anomalies appear to link to the track of volcanic chains and may indicate remnant near-melt.

\section{ACKNOWLEDGEMENTS}

This work was conducted at the Research School of Earth Sciences (RSES), Australian National University. The research was supported by the China Scholarship Council (grant 201604910731) and the AuScope AuSREM project, with additional support from National Natural Science Foundation of China (grants 41374065 and 41674060).

We thank the IRIS Data Management Center (http://ds.iris.edu/ $\mathrm{ds} /$ nodes/dmc) for waveform data for permanent stations, as well as the SKIPPY and KIMBA temporary deployments. The data for the other temporary stations were extracted from the archives at RSES.

We also thank Michelle Salmon for providing us the latest data for the depth of the Moho beneath the Australian continent. Figures were drawn with Generic Mapping Tools version 5.2.1.

\section{REFERENCES}

Akazawa, T., 2004. A technique for automatic detection of onset time of $P$-and $S$-phases in strong motion records, in Proc. of the 13th World Conf. on Earthquake Engineering, Vancouver, Canada.

Allen, R., 1978. Automatic earthquake recognition and timing from single traces, Bull. seism. Soc. Am., 68(5), 1521-1532.

Clitheroe, G., Gudmundsson, O. \& Kennett, B.L.N., 2000. The crustal thickness of Australia, J. geophys. Res., 105(B6), 13 697-13 713.

Conder, J.A. \& Wiens, D.A., 2006. Seismic structure beneath the Tonga arc and Lau back-arc basin determined from joint $V_{\mathrm{p}}, V_{\mathrm{p}} / V_{\mathrm{s}}$ tomography, Geochem. Geophys. Geosyst., 7(3), doi:10.1029/2005GC001113.

Cull, J.P., 1982. An appraisal of Australian heat-flow data, BMR J. Aust. Geol. Geophys., 7(1), 11-21.

Davies, D.R., Rawlinson, N., Iaffaldano, G. \& Campbell, I.H., 2015. Lithospheric controls on magma composition along Earth's longest continental hotspot track, Nature, 525(7570), 511-514.

de Kool, M. \& Kennett, B.L.N., 2014. Practical earthquake location on a continental scale in Australia using the AuSREM 3-D velocity model, Bull. seism. Soc. Am., 104, 2755-2767.

de Kool, M., Rawlinson, N. \& Sambridge, M., 2006. A practical grid-based method for tracking multiple refraction and reflection phases in threedimensional heterogeneous media, Geophys. J. Int., 167, 253-270.

Díaz, J., Gil, A. \& Gallart, J., 2012. Uppermost mantle seismic velocity and anisotropy in the Euro-Mediterranean region from $P n$ and $S n$ tomography, Geophys. J. Int., 192, 310-325.

Direen, N.G. \& Crawford, A.J., 2003. The Tasman Line: where is it, what is it and is it Australia's Rodinian breakup boundary?, Aust. J. Earth Sci., 50(4), 491-502.

Fichtner, A., Kennett, B.L.N., Igel, H. \& Bunge, H.-P., 2010. Full seismic waveform tomography for radially anisotropic structure: new insights into the past and present states of the Australasian upper mantle, Earth planet. Sci. Lett., 290, 270-280.

Fishwick, S. \& Rawlinson, N., 2012. 3-D structure of the Australian lithosphere from evolving seismic datasets, Aust. J. Earth Sci., 59(6), 809-826.

Fishwick, S. \& Reading, A.M., 2008. Anomalous lithosphere beneath the poterozoic of western and central Australia: a record of continental collision and intraplate deformation?, Precambrian Res., 166, 111-121.

Fishwick, S., Heintz, M., Kennett, B.L.N., Reading, A.M. \& Yoshizawa, K., 2008. Steps in lithospheric thickness within eastern Australia, evidence from surface wave tomography, Tectonics, 27(4) doi:10.1029/2007TC002116.

Goes, S. \& van der Lee, S., 2002. Thermal structure of the North American uppermost mantle inferred from seismic tomography, J. geophys. Res., 107(B3), ETG 2-1-ETG 2-13.

Huestis, S., Molnar, P. \& Oliver, J., 1973. Regional $S n$ velocities and shear velocity in the upper mantle, Bull. seism. Soc. Am., 63, 469-475.

Johnson, R.W. Knutson, J. \& Taylor, S.R. (eds), 1989. Intraplate Volcanism: in Eastern Australia and New Zealand, Cambridge Univ. Press.

Kennett, B.L.N., Engdahl, E.R. \& Buland, R., 1995. Constraints on seismic velocities in the Earth from traveltimes, Geophys. J. Int., 122, 108-124. 
Kennett, B.L.N., Fichtner, A., Fishwick, S. \& Yoshizawa, K., 2013. Australian seismological reference model (AuSREM): mantle component, Geophys. J. Int., 192, 871-887.

McLaren, S., Sandiford, M., Hand, M., Neumann, N., Wyborn, L. \& Bastrakova, I., 2003. The hot southern continent: heat flow and heat production in Australian poterozoic terranes, Geol. Soc. Am. Spec. Pap., 372, 157-167.

Nakajima, J., Matsuzawa, T., Hasegawa, A. \& Zhao, D., 2001. Threedimensional structure of $V_{\mathrm{p}}, V_{\mathrm{s}}$ and $V_{\mathrm{p}} / V_{\mathrm{s}}$ beneath northeastern Japan: Implications for arc magmatism and fluids, J. geophys. Res., 106, 21 $843-21857$.

Nicholson, C. \& Simpson, D.W., 1985. Changes in $V_{\mathrm{p}} / V_{\mathrm{s}}$ with depth: implications for appropriate velocity models, improved earthquake locations and material properties of the upper crust, Bull. seism. Soc. Am., 75, $1105-1123$.

Nolet, G., Coutlee, C. \& Clouser, R., 1998. Sn velocities in western and eastern North America, Geophys. Res. Lett., 25, 1557-1560.

Nur, A. \& Simmons, G., 1969. The effect of saturation on velocity in low porosity rocks, Earth planet. Sci. Lett., 7, 183-193.

Pei, S.P., Xu, Z.H. \& Wang, S.Y., 2004. Sn wave tomography of the uppermost mantle beneath the China continent and adjacent regions, Chin. J. Geophys., 47(2), 278-284.

Pei, S., Zhao, J., Sun, Y., Xu, Z., Wang, S., Liu, H. \& Gao, X., 2007. Upper mantle seismic velocities and anisotropy in China determined through $P n$ and $S n$ tomography, J. geophys. Res., 112(B5), doi:10.1029/2006JB004409.

Rawlinson, N. \& Sambridge, M., 2005. The fast marching method: an effective tool for tomographic imaging and tracking multiple phases in complex layered media, Explor. Geophys., 36(4), 341-350.

Rawlinson, N. \& Urvoy, M., 2006. Simultaneous inversion of active and passive source datasets for 3-D seismic structure with application to Tasmania, Geophys. Res. Lett., 33(24), doi:10.1029/2006GL028105.

Salmon, M., Kennett, B.L.N. \& Saygin, E., 2013a. Australian seismological reference model (AuSREM): crustal component, Geophys. J. Int., 192, 190-206.

Salmon, M., Kennett, B.L.N., Stern, T. \& Aitken, A.R.A., 2013b. The Moho in Australia and New Zealand, Tectonophysics, 609, 288-298.

Sambridge, M.S. \& Kennett, B.L.N., 2001. Seismic event location: nonlinear inversion using a neighbourhood algorithm, Pure appl. Geophys., 158(12), 241-257.

Shibutani, T., Sambridge, M. \& Kennett, B., 1996. Genetic algorithm inversion for receiver functions with application to crust and uppermost mantle structure beneath eastern Australia, Geophys. Res. Lett., 23, 1829-1832.

Sun, W. \& Kennett, B.L.N., 2016a. Uppermost mantle structure of the Australian continent from $P n$ traveltime tomography, J. geophys. Res., 121, 2004-2019.

Sun, W. \& Kennett, B.L.N., 2016b. Uppermost mantle structure beneath eastern China and its surroundings from $P n$ and $S n$ tomography, Geophys. Res. Lett., 43, 3143-3149.

Sun, Y., Toksöz, M.N., Pei, S. \& Morgan, F.D., 2008. The layered shear-wave velocity structure of the crust and uppermost mantle in China, Bull. seism. Soc. Am., 98, 746-755.

Trnkoczy, A., 2012. Topic Understanding and parameter setting of STA/LTA trigger algorithm, in New Manual of Seismological Observatory Practice 2 (NMSOP-2), pp. 1-20, ed. Bormann, P., Deutsches GeoForschungsZentrum GFZ.

Walck, M.C., 1988. Three-dimensional $V_{\mathrm{p}} / V_{\mathrm{s}}$ variations for the Coso region, California, J. geophys. Res., 93, 2047-2052.

Wei, Z., Kennett, B.L.N. \& Zhao, L.F., 2017. Lg-wave attenuation in the Australian crust, Tectonophysics, 717, 413-424.

Withers, M., Aster, R., Young, C., Beiriger, J., Harris, M., Moore, S. \& Trujillo, J., 1998. A comparison of select trigger algorithms for automated global seismic phase and event detection, Bull. seism. Soc. Am., 88, 95106.

Yoshizawa, K., 2014. Radially anisotropic 3-D shear wave structure of the Australian lithosphere and asthenosphere from multi-mode surface waves, Phys. Earth planet. Inter., 235, 33-48.

Zielhuis, A. \& Nolet, G., 1994. Shear-wave velocity variations in the upper mantle beneath central Europe, Geophys. J. Int., 117, 695-715.

\section{SUPPORTING INFORMATION}

Supplementary data are available at $G J I$ online.

Figure S1. Picking tool for $P n$ and $S n$ onsets. Key to marked features: $Z$, waveform on vertical component; R, waveform on radial component; $\mathrm{T}$, waveform on transverse component. These waveforms are cut within particular time windows. The time windows around the theoretical arrivals of $P n$ and $S n$ are $40 \mathrm{~s}$ wide. The brown vertical lines show times relative to the theoretical arrival times of $P n$ (red) and $S n$ (blue). ZE, square root energy on vertical component; HE, square root energy on horizontal component; E3, square root energy on all three components. Ze and $\mathrm{He}$ indicate the results of an STA/LTA analysis on the vertical and horizontal energy components. The pictures made by the coloured pixels are AR-grams ( $\mathrm{arH}$, the square root value of the sum of the squared fifth and sixth coefficients; arM, the square root value of the sum of the squared third and fourth coefficients; arL, the square root value of the sum of the squared first and second coefficients; Leonard \& Kennett 1999) and the small letter before each trace represents the name of the component. arD; the average values on the autocomponents ( $\mathrm{ZZ}$, $\mathrm{RR}, \mathrm{TT})$. arC, the average values on the cross-components (ZR, ZT, RT, RT, TR, TZ).

Figure S2. Traveltime residuals for $P n$ arrivals relative to the $a k 135$ model: (a) map for all $P n$ ray paths colour coded by the size of the residual before relocation and (b) map for $P n$ paths after relocation. Figure S3. Traveltime residuals for $P n$ arrivals relative to the $a k 135$ model for station FORT: (a) ray paths for $P n$ to station FORT before relocation; (b) ray paths after relocation; (c) histogram of $P n$ residuals at FORT before relocation; (d) histograms of $P n$ residuals at FORT after relocation.

Figure S4. Traveltime residuals, relative to the $a k 135$ model for $P n$ and $S n$ ray paths with epicentral distances less than $6^{\circ}$.

Figure S5. Resolution test for the $P n$-wave velocity model at 60 and $80 \mathrm{~km}$ depths. The horizontal slices show the original and recovered patterns and the vertical sections show the patterns along the longitude $144.1^{\circ}$ and latitude $-29.5^{\circ}$. The size of the checkerboard is $3.0^{\circ} \times 3.0^{\circ}$. The colour bar shows the size of velocity perturbation. The black lines indicate the depth to Moho.

Figure S6. Resolution tests for $S n$ - and $P n$-wave velocity model at $50 \mathrm{~km}$ depth. The horizontal slices show the original and recovered patterns, and the vertical sections show the patterns along the longitude $146.7^{\circ}$ and latitude $-29.5^{\circ}$ for $S n$ and the longitude $144.1^{\circ}$ and latitude $-29.5^{\circ}$ for $P n$. The size of the checkerboard is $3.0^{\circ} \times$ $3.0^{\circ}$. The colour bar shows the size of velocity perturbation. The black lines indicate the depth of the Moho.

Figure S7. Resolution tests for $S n$ - and $P n$-wave velocity model at $70 \mathrm{~km}$ depth. The horizontal slices show the original and recovered patterns, and the vertical sections show the patterns along the longitude $146.7^{\circ}$ and latitude $-29.5^{\circ}$ for $S n$ and the longitude $144.1^{\circ}$ and latitude $-29.5^{\circ}$ for $P n$. The size of the checkerboard is $3.0^{\circ} \times$ $3.0^{\circ}$. The colour bar shows the size of velocity perturbation. The black lines indicate the depth of the Moho.

Figure S8. Hypothesis tests for the $P n$-wave and $S n$-wave velocity models. The perturbations are centred at $50 \mathrm{~km}$ depth. The perturbations are circular shapes with a radius of $3^{\circ}$.

Figure S9. Resolution test for the $V_{\mathrm{p}} / V_{\mathrm{s}}$ model at 60 and $80 \mathrm{~km}$ depths. The horizontal slices show the original and recovered patterns, and the vertical sections show the patterns along the longitude $141.0^{\circ}$ and latitude $-29.5^{\circ}$. The size of the checkerboard is $3.0^{\circ} \times$ 
$3.0^{\circ}$. The colour bar shows the size of velocity perturbation. The black lines indicate the depth to Moho.

Figure S10. Maps of $S$-wave velocity from the initial model used in the inversion, at depths from 50 to $80 \mathrm{~km}$ with a step of $10 \mathrm{~km}$. The red dashed lines are craton boundaries. The light blue dashed line represents the Tasman Line.

Figure S11. Depth slices through the inverted $P n$-wave velocity model at depths of 50, 60, 70 and $80 \mathrm{~km}$. The red dashed lines are craton boundaries. The light blue dashed line represents the Tasman Line.

Please note: Oxford University Press is not responsible for the content or functionality of any supporting materials supplied by the authors. Any queries (other than missing material) should be directed to the corresponding author for the paper. 